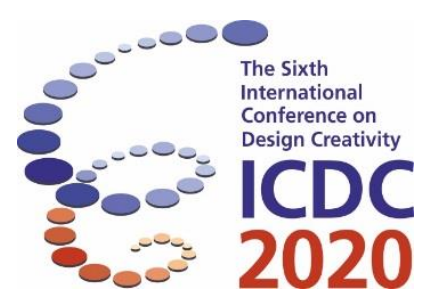

\title{
Participatory Design Research of Vegetable-based Snack Products with Adolescent Participants
}

\author{
Alice Gilmour, Steve Gill and Gareth Loudon \\ Art and Design, Cardiff Metropolitan University, Cardiff, Wales
}

\begin{abstract}
The childhood obesity epidemic is often attributed to the widespread marketing of High Fat, Salt and Sugar (HFSS) foods. Currently, there is a lack of vegetable-based New Product Development (NPD) targeting adolescent consumers. The study aimed to investigate adolescents' willingness to incorporate three vegetables: cauliflower, potatoes and cabbage into vegetable-based snack products. Two participatory design research sessions were conducted with Welsh adolescents aged 12- to 13-years-old ( $\mathrm{n}=41)$. The adolescents undertook three activities: (1) listing snack products currently eaten; (2) determining foods they associated with cauliflower, potatoes and cabbage; and, (3) designing a new vegetable-based snack product. Abductive thematic analysis resulted in four themes: taste preferences, commercial branding, convenience, and health consciousness. Developing healthy vegetable-based snack products could potentially improve the dietary quality of adolescents. This is one of the first participatory design research studies to include adolescents in the NPD process for healthy snack products.
\end{abstract}

Keywords: Participatory design research, New Product Development, Adolescents, Food choices, Vegetables.

\section{Background}

Promotional marketing techniques encouraging the overconsumption of HFSS foods and contemporary Western 'Obesogenic' environments with prevalent junk food outlets, price promotions and sweets at checkouts are often blamed as a major contributing factor to the childhood obesity epidemic (Birch \& Ventura, 2009; Lake \& Townshend, 2006). In contrast to the multimillion pound HFSS marketing that permeates modern society and childhoods, only $5 \%$ of the food marketing budget within the U.K. is spent on fruit and vegetables (The Food Foundation, 2018). Increased fruit and vegetable intake is widely recommended as part of a healthful diet and the UK government recommends eating five portions of fruit or vegetables daily (Public Health England, 2016). The vitamins, minerals and fibre found in fruits and vegetables are associated with reduced incidences of overweight, obesity, cardiovascular disease and cancer mortality (Slavin \& Lloyd, 2012; Wang et al., 2014; World Cancer Research Fund International, n.d.). Research has consistently revealed that the majority of adolescents do not meet the recommended dietary guidelines and have poor dietary habits. Only $8 \%$ of 11 - to 18 year-olds meet the 5-A-Day UK governmental fruit and vegetable consumption guideline, with the average daily fruit and vegetable portions being 2.8 (Public Health England and Food Standards Agency, 2016). Research has demonstrated that female adolescents prefer the taste of fruit and vegetables and eat on average 14.5 portions weekly in comparison to males who eat 11.9 portions (Bere, Brug, \& Klepp, 2008). Although this participatory design research was unable to clarify why females 
have these taste preferences, it may prove interesting to see how male and female adolescents' designs differ

The transitionary period of adolescence is important for physiological growth and psychological cognitive development, however can be problematic because increased autonomy may lead to unhealthful food consumption (Bassett, Chapman, \& Beagan, 2008; Viner et al., 2015). There is no universal definition of the term 'snack,' but this paper will refer to snacks as foods eaten by individuals on occasions outside of regular mealtimes (Hess, Jonnalagadda, \& Slavin, 2016). Snacks are often HFSS products such as crisps, chocolate and sweets which add discretionary calories to an individual's dietary intake (Cohen, Sturm, Scott, Farley, \& Bluthenthal, 2010). In recent years, numerous stealth vegetable-based NPD snacks have been brought to market for toddlers and young children. Meanwhile, there is a scarcity of healthful snacks targeting adolescents in the European market; therein stands a gap in the research and the market for a similar convenient healthful snacking product. Increasing vegetable liking by improving their sensory properties in an acceptable snack format may improve adolescents' dietary quality (Appleton et al., 2019). If healthful snacking products are acceptable for adolescent consumers then this has the potential to reduce consumption of unhealthful snacks and increase the health of adolescents. Improving the eating behaviour and attitudes developed during the period of adolescence is imperative because these will continue into adulthood and influence long-term health and weight status (Lake et al., 2004). The present study will contribute to the limited participatory design research literature involving adolescent participants and food. The research was conducted in collaboration with a grower's cooperative in Wales; hence, the vegetables specifically chosen for the research (cauliflower, potatoes and cabbage) were traditionally Welsh. The results in this conference paper are part of a larger research project.

\section{Methods}

\subsection{Participants}

Overall, forty-one adolescents aged 12- to 13-years old took part in the two participatory design research sessions, $59 \%$ were female $(n=24)$ and $41 \%$ were male $(n=17)$. Participants were convenience sampled from a comprehensive secondary school in South Wales, UK. Free School Meal (FSM) rates were used as a measure of Socio-economic Status (SES), with the most recent average for the local authority being 18\% in 2018 (Gorard, 2012; The Children's Society, 2018). Thus, the school studied was considered representative of middle-class SES adolescents due to its lower than average 11.6\% FSM take-up. Access to the adolescent pupil participants was obtained through directly convening with the head teacher and the School Food Coordinator. Ethical approval was attained from the ethics committee at the university affiliated with the researchers. Upon agreement that the researcher would not be using audio-recording equipment, nor speaking to or interacting with any of the participants, parental consent was not necessary. The School Food Coordinator acted in loco parentis for the adolescent participants who provided verbal assent. No incentives or compensation were given to the participants.

\subsection{Procedure}

This study involved both qualitative and quantitative data collection methods to investigate adolescents' acceptance of novel stealth vegetable-based snack products. The participatory design research sessions involved three activities led by the School Food Coordinator. Conducting the sessions within a school food technology classroom provided a familiar, reassuring environment for the participants (Phelan \& Kinsella, 2013). A variety of activities were incorporated into the sessions (i.e., listing, associations, designing), enabling participants to work as a whole group, individually, in pairs and in groups. The diversity of activities and group work were designed to stimulate creativity and encouraged collaboration and discussion whilst maintaining the adolescents' attention throughout (Iversen, Dindler, \& Hansen, 2013; Robertson \& Wagner, 2013). During the session, verbatim spoken quotes from the participants and field notes were recorded in writing by the lead author. Following the completion of the participatory research design, worksheets were collected for analysis. 


\subsection{Discussion guide}

The discussion guide was designed to answer the research questions through the collection of quantitative and qualitative data. The guide was conveyed verbally and in writing to the School Food Coordinator who carried out the sessions. Initially, participants were introduced to the study. After this, they were each provided with blank sheets of paper and worked in groups of two to three to either list or mind map the snacks that they regularly ate (Activity One). This activity was designed to be an easy warm-up activity to encourage engagement from all participants. After this, participants were asked to put their hand up if they liked cauliflower, potatoes or cabbage. The whole group of adolescents considered which products they associated with the vegetables and these were listed on the whiteboard (Activity Two). Next, participants were told that a fictional food company was going to launch a new sweet or savoury product that included at least one of the three aforementioned vegetables (cauliflower, potatoes, cabbage). The participants were given coloured pencils and a worksheet with the design brief: 'design four new snack products using these vegetables.' Participants were asked to draw the product, packaging and label their designs (Activity Three). Design tasks seldom occur on the school curriculum, so the School Food Coordinator advised that individuals were given the opportunity to choose whom they wanted to work with: individually, in pairs or in groups of three.

\section{Data Analysis and Results}

The assortment of activities produced various qualitative and quantitative data. This included mind maps, lists, drawings and the lead author's field notes. The quantitative data collected during the activities were subject to descriptive statistical analysis generated using Microsoft Office Excel software. The qualitative data was studied initially to identify whether any patterns or themes reoccurred. Braun and Clarke's six phases of thematic analysis were applied in an abductive manner: (1) Familiarisation with the data; (2) Coding; (3) Searching for themes; (4) Reviewing themes; (5) Defining and naming themes; and, (6) Writing up. An open coding, abductive approach was utilised because codes emerged from the data for categorisation but were also influenced by the existing literature (Braun \& Clarke, 2006, 2013). The qualitative data was coded using the QSR NVivo10 (Copyright巴 QSR International Pty Ltd) qualitative analysis software (Bazeley \& Jackson, 2013). Organising the qualitative data into themes through grouping reoccurring codes allowed for further analysis (Maxwell, 2013). The four themes that abductively emerged from the thematic analysis were: taste preferences, commercial branding, convenience, and health consciousness. These themes will be discussed in detail in the Discussion section; but here the results from each of the three activities will be presented in turn. Results are available in an Appendix online: 10.25401/cardiffmet.12082992.

\subsection{Snacks frequently consumed by adolescents}

Across the two research sessions, 13 groups of two or three adolescents were formed. In total, 251 snack products were named. The most popular snacks listed were: chocolate $(n=13)$, cheeses $(n=12)$, crisps $(n=10)$, carrots $(n=9)$ and biscuits $(n=8)$. Snacks were categorised and the rate of occurrence were as follows: savoury snacks / baked goods $(n=61)$, fruit $(n=59)$, sweet snacks / baked goods $(n=49)$, confectionery $(n=29)$, vegetables $(n=23)$, drinks $(n=11)$, 'fast food' $(n=10)$, and nuts and seeds $(n=9)$. Confectionery items, sweet baked goods and sweet goods totalled $43 \%$ of all snacks $(n=108)$. The tendency was to write generic products, with commercial brands merely making up 5.6\% $(n=14)$ of the snack products named.

\subsection{Adolescents' vegetable liking and associated foods}

Out of the three Welsh vegetables concerned in the study, potatoes were the most favoured (95\%), followed by cauliflower (44\%) and cabbage (41\%). Across both sessions, the most product associations were made for potatoes $(n=18)$, in contrast to cauliflower $(n=8)$ and cabbage $(n=7)$. Whilst common products such as chips, potato waffles and roast dinners were recalled, other more unusual products were mentioned. These included kimchi, sauerkraut, potato doughnuts and cauliflower steak. 


\subsection{Concepts drawn in response to the design brief}

In total, 29 worksheets with a total of 95 design concepts were produced (see Figure 1 and Table 1). Some responses were imitative, such as heart-shaped potato bites, a mixed vegetable tart and potato doughnuts. However, several were inventive, for instance, cupcake cases made with marinated cabbage, cauliflower ice-cream, a berry and apple smoothie featuring cabbage as well as a cauliflower "breakfast go ball" containing cauliflower, cocoa, hemp seed and chia seeds. Some compelling product names included "Speedy Spud," "The All in One Roast Dinner," "Cabbleberry Smoothie" and "Prawnflower Curry." Further, a few responses involved the notion of "trickery" and the incorporation of stealth vegetables:

- "This lollipop is made of candies with a good baked potato. This will make kids think that this is a sweet lollipop but when they reach the inside, the sweet potato will fill their mouth."

- "It's deep fried cabbage slices in a crisp packet that you offer to your friend thinking it's a crisp and they bite into it, and it's disgusting."
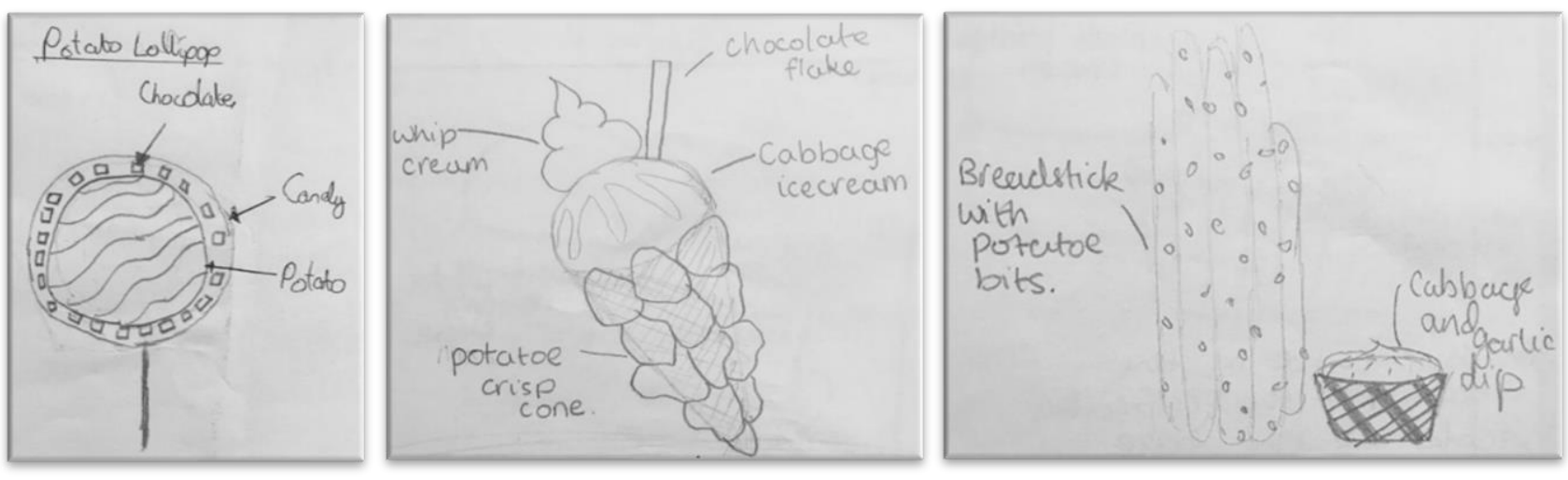

Figure 1. Examples of the drawings produced by adolescent participants

Table 1. Descriptive statistics of occurrences within participants' responses to the design brief

\begin{tabular}{|c|c|c|c|c|c|c|}
\hline Ideas & Males & \% Male & Females & \% Female & Total & $\begin{array}{c}\text { Average } \\
\text { Percentage }\end{array}$ \\
\hline Total number of ideas & 41 & $43 \%$ & 54 & $57 \%$ & 95 & $100 \%$ \\
\hline Sweet & 7 & $17 \%$ & 12 & $22 \%$ & 19 & $20 \%$ \\
\hline Savoury & 34 & $83 \%$ & 42 & $78 \%$ & 76 & $80 \%$ \\
\hline Includes cauliflower & 22 & $54 \%$ & 23 & $43 \%$ & 45 & $47 \%$ \\
\hline Includes potato & 23 & $56 \%$ & 29 & $54 \%$ & 52 & $55 \%$ \\
\hline Includes cabbage & 11 & $27 \%$ & 18 & $33 \%$ & 29 & $31 \%$ \\
\hline
\end{tabular}

Positively, all of the designs produced contained at least one of the required vegetables. However, the male participants' drawings incorporated cabbage with half the frequency $(n=11)$ compared to the potato $(n=23)$ and cauliflower $(n=22)$ occurrences. Only $20 \%$ of responses were sweet, the majority drawn were savoury product concepts.

Ten design elements were identified, five sketched elements and five written elements (see Table 2). The most frequently included elements in the drawings were the product image (100\%), packaging image $(29.5 \%)$ and the ingredient image(s) (58.9\%). Gender differences were apparent as none of the male participants included a price and none of the female participants included a product character. Several participants wrote about the environmental credentials of their product. This compromised recyclable packaging, recycled plastic and wrapping the product in potato starch instead of plastic. 
Table 2. Descriptive statistics of packaging design elements

\begin{tabular}{|c|c|c|c|}
\hline Design Elements & $\begin{array}{c}\text { Males } \\
\text { n(\%) }\end{array}$ & $\begin{array}{c}\text { Females } \\
\text { n (\%) }\end{array}$ & $\begin{array}{c}\text { Overall } \\
\text { n (\%) }\end{array}$ \\
\hline Sketched & \multicolumn{3}{|c|}{} \\
\hline Product image & $41(100 \%)$ & $54(100 \%)$ & $95(100 \%)$ \\
\hline Packaging image & $7(17.1 \%)$ & $21(38.9 \%)$ & $28(29.5 \%)$ \\
\hline Ingredient image(s) & $25(61 \%)$ & $31(57.4 \%)$ & $56(58.9 \%)$ \\
\hline Price & $0(0 \%)$ & $8(14.8 \%)$ & $8(8.4 \%)$ \\
\hline Character & $4(9.8 \%)$ & $0(0 \%)$ & $4(4.2 \%)$ \\
\hline Written $\quad 11(27 \%)$ & $8(14.8 \%)$ & $20(21.1 \%)$ \\
\hline Creative product name & $15(36.7 \%)$ & $19(35.2 \%)$ & $34(35.8 \%)$ \\
\hline Descriptive text & $24(58.5 \%)$ & $33(61.1 \%)$ & $57(60 \%)$ \\
\hline Detailed ingredient labelling & $2(4.9 \%)$ & $1(1.9 \%)$ & $3(3.6 \%)$ \\
\hline Health claim & $2(4.9 \%)$ & $8(14.8 \%)$ & $10(10.5 \%)$ \\
\hline Packaging descriptions &
\end{tabular}

\section{Discussion}

The results from this study demonstrated that adolescents aged 12- to 13-years-old were enthusiastic about participating in the design of vegetable-based snack products and their insight is of value academically and commercially. Four key themes appeared to influence adolescents' responses: taste preferences, commercial branding, convenience, and health consciousness.

First, taste preferences and familiarity of vegetables and their incorporation in existing dishes seemed to be a key factor in the designs produced by the adolescents. $80 \%$ of the drawings were savoury, indicating that the adolescents associated cauliflower, potato and cauliflower predominantly with savoury rather than sweet products. This is likely to have resulted from their early-life experiences, parenting, family, culture, and socio-economic environment which will have shaped their attitudes towards foods (Scaglioni, Cosmi, Ciappolino, Brambilla, \& Agostoni, 2018). Predictably, Activity Two revealed that the vast majority liked potatoes. Potatoes are a favourable, familiar ingredient in many dishes as well as unhealthful HFSS snacking products. Familiarity with ingredients is vital and a previous study with individuals aged 8- to 14-years-old revealed that when participants were given labelled or unlabelled snack foods containing vegetables, taste perceptions were negatively impacted when the ingredient was unfamiliar. In this case, taste preferences remained consistent for the zucchini and broccoli products, but as only 19\% had eaten chickpeas within the last year, chickpeas were least familiar and the 'chickpea chocolate chip cookies' were perceived most negatively (Pope \& Wolf, 2012). Although cauliflower was favoured over cabbage and featured in more designs, potato-based designs prevailed. Bitterly tasting vegetables lack sensory appeal for adolescents and any further NPD should take this into consideration when designing for this target market (Appleton et al., 2019).

Commercial branding seemed largely irrelevant when the adolescents listed or mind mapped the snack products they currently ate during Activity One. Comparably, a previous study involving 7- to 12-yearolds asked participants to list the snacks that they ate, and many more branded products were listed than in this current study (Letona, Chacon, Roberto, \& Barnoya, 2014). The lack of products listed was surprising because snacks are often socially visible and research has found that some adolescents are very self-conscious about consuming products with generic supermarket-own label brands amongst their peer group, preferring commercial products that are 'cool' (Roper \& La Niece, 2009; Stead, McDermott, Marie, \& Adamson, 2011). Similarly, a quantitative study investigating 14-year-olds Instagram use discovered that $44.7 \%$ of the photographs shared included the brand name (Holmberg Chaplin, Hillman, \& Berg, 2016). Marketers and packaging designers strategically use packaging on commercially branded products as an integral communication point for consumers, communicating its positioning and branding through the packaging (Ahmed, Ahmed, \& Salman, 2005). Thus, it was 
expected that more brands would be mentioned throughout the study. As this part of the study was recorded quantitatively, it is impossible to understand why such a small amount (5.6\%) of the snack products listed featured a brand name because the literature suggests that commercial branding is valuable for this target market.

The theme of convenience was common amongst the snacks listed in Activity One and most designs in Activity Three were packaged or suitable for consumption on-the-go. This finding is in support of the literature, for example a study with 6- to 12-year-olds showed that taste preferences as well as accessibility and availability of fruit and vegetables was imperative to an individuals' intake (Blanchette $\&$ Brug, 2005). Even the inconvenience of peeling fruit has been highlighted as a barrier for adolescents' consumption of health foods (Neumark-Sztainer, Story, Perry, \& Casey, 1999). Remarkably, all the snack product designs in Activity Three did not require cutlery. Prior studies investigating attitudes towards cutlery use is sparse, but this omission of cutlery is supported by an adolescent focus group study which revealed individuals avoided foods requiring cutlery because using it would be an 'embarrassment' (Stead et al., 2011). Moreover, whilst adolescents do not appreciate food preparation skills, convenience is highly regarded by adolescent consumers, yet they often perceive convenience products to have negative health implications (Wahlen, van der Horst, \& Pothoff, 2016). Therefore, it is important that NPD targeting this market ensure that snacking products are convenient yet also suitably healthful.

Lastly, health consciousness was evident throughout all three activities to a small degree. Only three designs included a health claim, but other designs alluded to the calorific content or included a descriptive product tagline encouraging healthful eating or explaining the health benefits of consuming the product. This awareness of healthful eating is indicative of the adolescents' nutritional knowledge. Nevertheless, like adults, whilst adolescents may be aware of the importance of a healthful diet, this knowledge alone is often not a worthy enough motivating factor for them. An overall lack of health consciousness was expected, as the literature shows adolescents tend to prioritise other factors such as taste preferences, peer influence, convenience and availability more urgently (Larson, Laska, Story, \& Neumark-Sztainer, 2012; Nga et al., 2019). Notably, the participants may have been reluctant to demonstrate health consciousness as it may have not been socially acceptable. The presence of peers has been found to produce internal conflict when adolescents are weighing up health versus indulgence in light of the peer groups' snacking social conventions (Bech-Larsen, Jensen, \& Pedersen, 2010). Perhaps if all the participants had done Activity Three individually then they may have felt less social pressures and more willingly displayed health consciousness aspects in their designs.

To our knowledge, this is one of the first participatory design research studies to include adolescents in the NPD process for healthful snack products. A strength of the study is that the findings contribute to the limited body of research regarding adolescents' acceptance of novel vegetable-based snack products. The methodology used and the incorporation of a variety of activities helped to maintain the adolescents' engagement in the study and their motivation to contribute to the NPD process. Representation of adolescents' perspectives in research is important because they are social actors in their environment (James, 2007). However, one limitation is that the findings from a convenience sample of middle-class SES adolescent participants cannot be extrapolated to the entire adolescent population. Thus, we are unable to comment on the extent to which the findings are applicable to adolescents living in more socially disadvantaged areas.

\section{Conclusion}

This paper aimed to investigate adolescents' willingness to incorporate traditionally Welsh vegetables into novel stealth vegetable-based snack products. The current study adds to the limited participatory design research literature involving adolescent participants and food. The study findings could provide a basis for further investigative or explorative research as well as commercial NPD of vegetable-based snacking products. Developing age-appropriate vegetable-based snacking products has the potential to improve current dietary behaviour and increase vegetable consumption as long as snacks taste preferable and are in a convenient format. Further research is required concerning marketing, packaging and NPD, perhaps incorporating the taste testing of flavour combinations with a larger sample size. The 
use of adolescent participants to help influence decision-making is encouraged, as their input regarding acceptability can be enlightening, as exhibited in this study.

\section{Acknowledgement}

Funding from a Knowledge Economy Skills Scholarship (KESS2) and support from Puffin Produce are gratefully acknowledged by the authors.

\section{References}

Ahmed, A., Ahmed, N., \& Salman, A. (2005). Critical issues in packaged food business. British Food Journal, 107(10), 760-780. https://doi.org/10.1108/00070700510623531

Appleton, K. M., Dinnella, C., Spinelli, S., Morizet, D., Saulais, L., Hemingway, A., ... Hartwell, H. (2019). Liking and consumption of vegetables with more appealing and less appealing sensory properties: Associations with attitudes, food neophobia and food choice motivations in European adolescents. Food Quality and Preference, 75, 179-186. https://doi.org/10.1016/j.foodqual.2019.02.007

Bassett, R., Chapman, G. E., \& Beagan, B. L. (2008). Autonomy and control: The co-construction of adolescent food choice. Appetite, 50(2-3), 325-332. https://doi.org/10.1016/j.appet.2007.08.009

Bazeley, P., \& Jackson, K. (2013). Qualitative Data Analysis with NVivo. SAGE Publications, London.

Bech-Larsen, T., Jensen, B. B., \& Pedersen, S. (2010). An exploration of adolescent snacking conventions and dilemmas. Young Consumers, 11(4), 253-263. https://doi.org/10.1108/17473611011093899

Bere, E., Brug, J., \& Klepp, K. I. (2008). Why do boys eat less fruit and vegetables than girls? Public Health Nutrition, 11(3), 321-325. https://doi.org/10.1017/S1368980007000729

Birch, L., \& Ventura, A. (2009). Preventing childhood obesity: What works? International Journal of Obesity, 33(1), 74-81. https://doi.org/10.1038/ijo.2009.22

Blanchette, L., \& Brug, J. (2005). Determinants of fruit and vegetable consumption among 6-12-year-old children and effective interventions to increase consumption. Journal of Human Nutrition and Dietetics, 18(6), 431-443. https://onlinelibrary.wiley.com/doi/10.1111/j.1365-277X.2005.00648

Braun, V., \& Clarke, V. (2006). Using thematic analysis in psychology. Qualitative Research in Psychology, 3(3), 77-101. https://doi.org/10.1017/CBO9781107415324.004

Braun, V., \& Clarke, V. (2013). Successful Qualitative Research: A Practical Guide for Beginners (First). SAGE Publications, London.

Cohen, D. A., Sturm, R., Scott, M., Farley, T. A., \& Bluthenthal, R. (2010). Not enough fruit and vegetables or too many cookies, candies, salty snacks, and soft drinks? Public Health Reports, 125(1), 88-95. https://doi.org/10.1177/003335491012500112

Gorard, S. (2012). Who is eligible for free school meals? Characterising free school meals as a measure of disadvantage in England. British Educational Research Journal, 38(6), 1003-1017. https://doi.org/10.1080/01411926.2011.608118

Hess, J. M., Jonnalagadda, S. S., \& Slavin, J. L. (2016). What is a snack, Why do we snack, and How can we choose better snacks? A review of the definitions of snacking, motivations to snack, contributions to dietary intake, and recommendations for improvement. Advances in Nutrition, 7(3), 466-475. https://doi.org/10.3945/an.115.009571

Holmberg, C., E. Chaplin, J., Hillman, T., \& Berg, C. (2016). Adolescents' presentation of food in social media: An explorative study. Appetite, 99, 121-129. https://doi.org/10.1016/j.appet.2016.01.009

Iversen, O., Dindler, C., \& Hansen, E. (2013). Understanding teenagers' motivation in participatory design. International Journal of Child-Computer Interaction, 1(3-4), 82-87. https://doi.org/10.1016/j.ijcci.2014.02.002

James, A. (2007). Giving voice to children's voices: Practices and problems, pitfalls and potentials. American Anthropologist, 109(2), 261-272. https://doi.org/10.1525/aa.2007.109.2.261

Lake, A. A., Rugg-Gunn, A. J., Hyland, R. M., Wood, C. E., Mathers, J. C., \& Adamson, A. J. (2004). Longitudinal dietary change from adolescence to adulthood: Perceptions, attributions and evidence. Appetite, 42(3), 255-263. https://doi.org/10.1016/j.appet.2003.11.008

Lake, A., \& Townshend, T. (2006). Obesogenic environments: Exploring the built and food environments. Journal of The Royal Society for the Promotion of Health, 126(6), 262-267. https://doi.org/10.1177/1466424006070487

Larson, N., Laska, M., Story, M., \& Neumark-Sztainer, D. (2012). Predictors of fruit and vegetable intake in young adulthood. Journal of the Academy of Nutrition and Dietetics, 112(8), 1216-1222. https://doi.org/10.1016/j.jand.2012.03.035 
Letona, P., Chacon, V., Roberto, C., \& Barnoya, J. (2014). A qualitative study of children's snack food packaging perceptions and preferences. BMC Public Health, 14(1), 1-6. https://doi.org/10.1186/1471-2458-14-1274

Maxwell, J. (2013). Qualitative Research Design: An Interactive Approach. Third Edition. SAGE, England.

Neumark-Sztainer, D., Story, M., Perry, C., \& Casey, M. (1999). Factors influencing food choices of adolescents. Journal of the American Dietetic Association. https://doi.org/10.1016/S0002-8223(99)00222-

Nga, V. et al. (2019). School education and childhood obesity: A systemic review. Diabetes and Metabolic Syndrome: Clinical Research and Reviews, 13(4), 2495-2501. https://doi.org/10.1016/j.dsx.2019.07.014

Phelan, S. K., \& Kinsella, E. A. (2013). Picture this... Safety, dignity, and voice - Ethical research with children: Practical considerations for the reflexive researcher. Qualitative Inquiry, 19(2), 81-90. https://doi.org/10.1177/1077800412462987

Pope, L., \& Wolf, R. L. (2012). The influence of labeling the vegetable content of snack food on children's taste preferences: A pilot study. Journal of Nutrition Education and Behavior, 44(2), 178-182. https://doi.org/10.1016/j.jneb.2010.02.006

Public Health England. (2016). New Eatwell Guide illustrates a healthy, balanced diet. Retrieved September 6, 2019, from https://www.gov.uk/government/news/new-eatwell-guide-illustrates-a-healthy-balanced-diet

Public Health England and Food Standards Agency. (2016). National Diet and Nutrition Survey: Results from Years 5 and 6 (combined) of the Rolling Programme (2012/2013-2013/2014). Retrieved from https://www.gov.uk/government/uploads/system/uploads/attachment_data/file/551352/NDNS_Y5_6_UK_Main _Text.pdf

Robertson, T., \& Wagner, I. (2013). Ethics. In J. Simonsen \& T. Robertson (Eds.), Routledge international handbook of participatory design (pp. 64-85). New York: Routledge.

Roper, S., \& La Niece, C. (2009). The importance of brands in the lunch-box choices of low-income British school children. Journal of Consumer Behaviour, 8, 84-99. https://doi.org/10.1002/cb

Scaglioni, S., Cosmi, V. De, Ciappolino, V., Brambilla, P., \& Agostoni, C. (2018). Factors influencing children's eating behaviours. Nutrients, 10(6), 1-17. https://doi.org/10.3390/nu10060706

Slavin, J., \& Lloyd, B. (2012). Health Benefits of Fruits and Vegetables. Advantages in Nutrition, 3(4), 506-516. https://doi.org/10.3945/an.112.002154.506

Stead, M., McDermott, L., Marie, A., \& Adamson, A. (2011). Why healthy eating is bad for young people's health: Identity, belonging and food. Social Science \& Medicine, 72(7), 1131-1139. https://doi.org/10.1016/j.socscimed.2010.12.029

The Children's Society. (2018). Welsh Government consultation on revised eligibility criteria for free school meals in Wales due to rollout of Universal Credit The Children's Society (Vol. 1).

The Food Foundation. (2018). UK's annual fruit and veg advertising budget used up just 19 days into the new year. Retrieved October 31, 2019, from https://foodfoundation.org.uk/uks-annual-fruit-and-veg-advertisingbudget-used-up-just-19-days-into-the-new-year/

Viner, R., Ross, D., Hardy, R., Kuh, D., Power, C., Johnson, A., ... Batty, G. (2015). Life course epidemiology: Recognising the importance of puberty. Journal of Epidemiology and Community Health, 69(8), 719-720. https://doi.org/10.1136/jech-2015-205607

Wahlen, S., van der Horst, H., \& Pothoff, R. (2016). How convenient!? Adolescents' vistas on food competences in a convenience context. British Food Journal, 118(11), 2828-2838. https://doi.org/10.1108/BFJ-12-2015-0479 Wang, X., Ouyang, Y., Liu, J., Zhu, M., Zhao, G., Bao, W., \& Hu, F. B. (2014). Fruit and vegetable consumption and mortality from all causes, cardiovascular disease, and cancer: Systematic review and dose-response metaanalysis of prospective cohort studies. BMJ (Online), 349(July), 1-14. https://doi.org/10.1136/bmj.g4490

World Cancer Research Fund International. (n.d.). Poor diet and cancer risk: Can unhealthy eating give you cancer? Retrieved December 31, 2019, from https://www.wcrf-uk.org/uk/preventing-cancer/what-can-increaseyour-risk-cancer/poor-diet-and-cancer-risk 